\title{
Spatiotemporal changes in agricultural land cover in Nepal over the last 100 years
}

\author{
Basanta PAUDEL ${ }^{1,2},{ }^{*}$ ZHANG Yili ${ }^{1,2,3}$, LI Shicheng ${ }^{1,2,4}$, LIU Linshan ${ }^{1}$ \\ 1. Key Laboratory of Land Surface Pattern and Simulation, Institute of Geographic Sciences and Natural Re- \\ sources Research, CAS, Beijing 100101, China; \\ 2. University of Chinese Academy of Sciences (UCAS), Beijing 100049, China; \\ 3. CAS Center for Excellence in Tibetan Plateau Earth Sciences, Beijing 100101, China; \\ 4. School of Public Administration, China University of Geosciences, Wuhan 430074, China
}

\begin{abstract}
In order to advance land use and land cover change (LUCC) research in Nepal, it is essential to reconstruct both the spatiotemporal distribution of agricultural land cover as well as scenarios that can explain these changes at the national and regional levels. Because of rapid population growth, the status of agricultural land in Nepal has changed markedly over the last 100 years. Historical data is used in this study, encompassing soils, populations, climatic variables, and topography. Data were revised to a series of $30 \mathrm{~m}$ grid cells utilized for agricultural land suitability and allocation models and were analyzed using a suite of advanced geographical tools. Our reconstructions for the spatiotemporal distribution of agricultural land in Nepal reveal an increasing trend between 1910 and 2010 (from $151.2 \times 10^{2} \mathrm{~km}^{2}$ to $438.8 \times 10^{2} \mathrm{~km}^{2}$ ). This expanded rate of increase in agricultural land has varied between different eco, physiographic, and altitudinal regions of the country, significantly driven by population changes and policies over the period of this investigation. The historical dataset presented in this paper fills an existing gap in studies of agricultural land change and can be applied to other carbon cycle and climate modeling studies, as well as to impact assessments of agricultural land change in Nepal.
\end{abstract}

Keywords: agricultural land; reconstruction; land suitability for cultivation; altitudinal variation; Nepal

\section{Introduction}

Studies on land use and land cover change (LUCC) at global and regional scales have shown that large environmental and ecological changes are often due to human activities (Klein Goldewijk and Ramankutty, 2004; Foley et al., 2005; Fuchs et al., 2015; Yang et al., 2015). Marked changes in global population, high levels of industrial development, and advances in

Received: 2017-05-09 Accepted: 2017-07-27

Foundation: National Natural Science Foundation of China, No.41371120; International Partnership Program of Chinese Academy of Sciences, No.131C11KYSB20160061; The Chinese Academy of Sciences - The World Academy of Sciences (CAS-TWAS) President's Fellowship Program for PhD Study

Author: Basanta Paudel, PhD Candidate, specialized in land use/land cover change and climate change adaptation. E-mail: paudelb@igsnrr.ac.cn

*Corresponding author: Zhang Yili, Professor, E-mail: zhangyl@igsnrr.ac.cn 
technology have all been proposed as key factors driving LUCC (Lambin et al., 2001). Research in this area and on global change generally has increased continuously over recent decades at a large number of different academic institutions and organizations (Ramankutty and Foley, 1999; Chen et al., 2015), with all available data often being brought to bear in historical reconstructions of land use change (Yang et al., 2015).

The analysis of spatially explicit data within climate and ecosystem models has proved the most effective approach for understanding LUCC (He et al., 2015). At the same time, however, numerical simulations have also been applied in this field (Pitman et al., 2011), especially in research on changing agricultural and cropland coverage (He et al., 2012; He et al., 2013; Zhang et al., 2013; Li et al., 2016; Li et al., 2017; Paudel et al., 2017). The use of map-based long-term historical analysis of agricultural land patterns has proved the most effective method to demonstrate changing trends, as such approaches are spatially explicit. To date, such methods have been successfully applied to the reconstruction of long-term LUCC (Fuchs et al., 2013), in particular changes in agricultural and cropland cover, at both temporal and spatial scales (He et al., 2015; Li et al., 2016; Paudel et al., 2017).

A number of excellent benchmark studies have been carried out in this field, generating historical spatial datasets for research in particular on cropland change at global scales (Ramankutty and Foley, 1999; Pongratz et al., 2008). A good deal of attention has been paid to historical LUCC reconstructions using high-resolution spatial data, leading, for example, to the development of the History Database of the Global Environment (HYDE) and the Sustainability and the Global Environment (SAGE) dataset (Ramankutty and Foley, 1999; Klein Goldewijk et al., 2011). The latter of these two global datasets encompasses the distribution of cropland between 1700 and 1992 at $0.5^{\circ}$ resolution, while the former was developed, and is now available, in four versions. HYDE versions 3.1 and 3.2 are the latest iterations and incorporate several factors, including population, distance to the nearest river, slope, distribution of urban area, forest, and potential vegetation. These versions contain a series of long-term (the last 12,000 years, over the Holocene) historical datasets (Klein Goldewijk, 2017); reconstructions using these data have so far been carried out in a number of different regions, utilizing a range of different techniques and models for the reconstruction of long-term LUCC (Wei et al., 2015; Yang et al., 2015).

Global-level datasets such as SAGE and HYDE capture general trends in the long-term status of LUCC. In the context of Nepal, while a number of initial historical LUCC and agricultural land cover studies were conducted, they only encompassed small areas of the country over short time periods (Paudel et al., 2016b). Subsequently, however, two national-level LUCC datasets have been developed (Land Resources Mapping Project [LRMP], 1986; Uddin et al., 2015), incorporating advances in aerial photography and satellite systems and utilizing remote sensing and geographic information system technologies. Thus, one recent study has been carried out to determine spatiotemporal patterns of agricultural land between 1970 and 2010 and to fill in historical LUCC national data gaps (Paudel et al., 2017). Again, however, recent datasets also only consider the status of agricultural land over the last 50 years within Nepal; because other national scale datasets also only consider very specific time periods, previous work has been unable to elucidate long-term changes and trends in LUCC as well as the status of agricultural lands. 
The aim of this historical study of agricultural land change was therefore to create and reconstruct long-term spatial datasets of agricultural land distributions at $30 \mathrm{~m} \times 30 \mathrm{~m}$ resolution for Nepal over the last 100 years (between 1910 and 2010) at 10-year intervals. This study thus provides a series of much-needed historical spatial datasets for the country.

\section{Study area and methods}

\subsection{Study area}

Nepal, the study area for this research, is a land-locked country located adjacent to China and India in the central Himalayas between latitudes $26^{\circ} 22{ }^{\prime} \mathrm{N}$ and $30^{\circ} 27^{\prime} \mathrm{N}$ and longitudes $80^{\circ} 04^{\prime} \mathrm{E}$ and $88^{\circ} 12^{\prime} \mathrm{E}$ (Figure 1a). This country comprises five physiographic regions, Tarai, Siwalik, and Hill, as well as the Middle and High Mountains, encompasses an area of $147,181 \mathrm{~km}^{2}$ (LRMP, 1986), has a population of 28.5 million (2015), and had a per capita gross domestic product (GDP) of 732.3 US\$ in 2015 (World Bank, 2015). Data show that the average

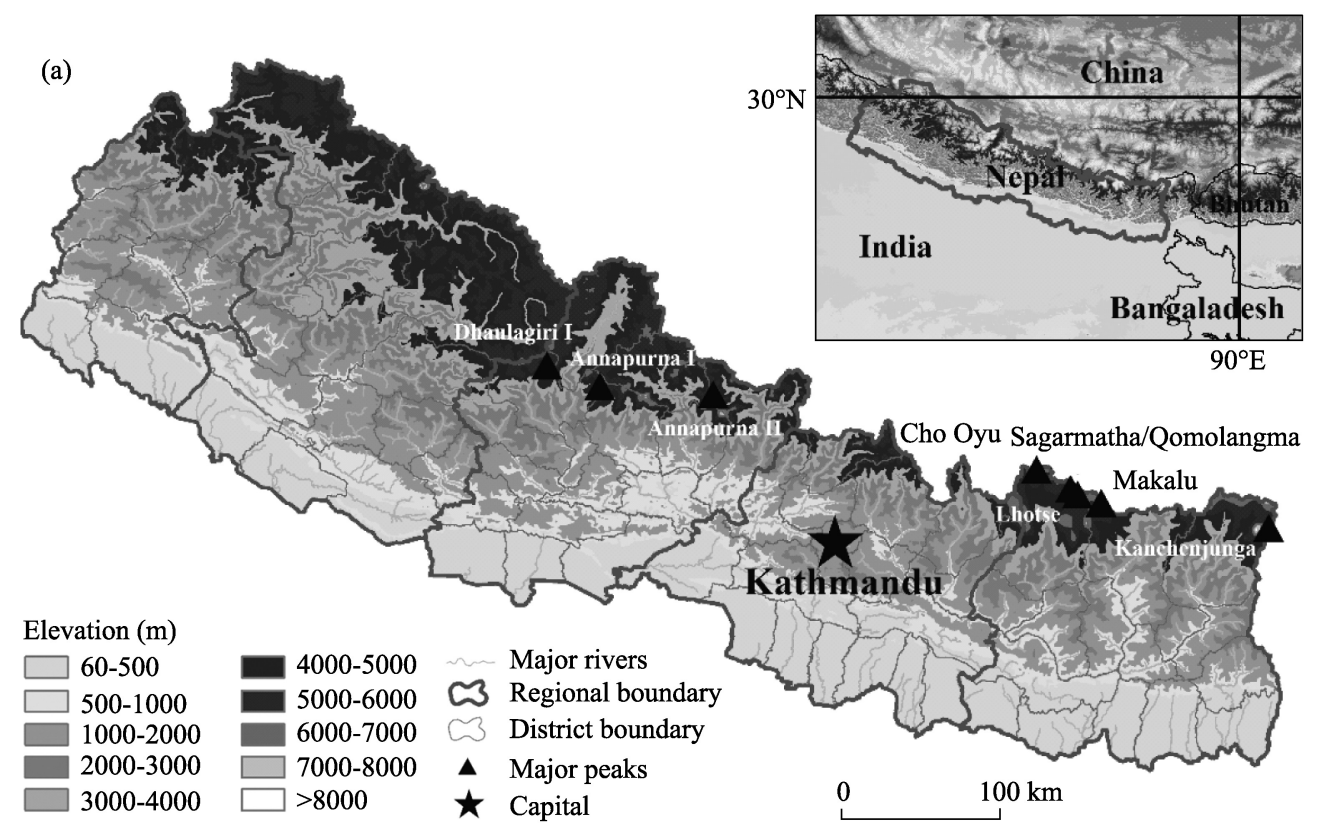

(b)

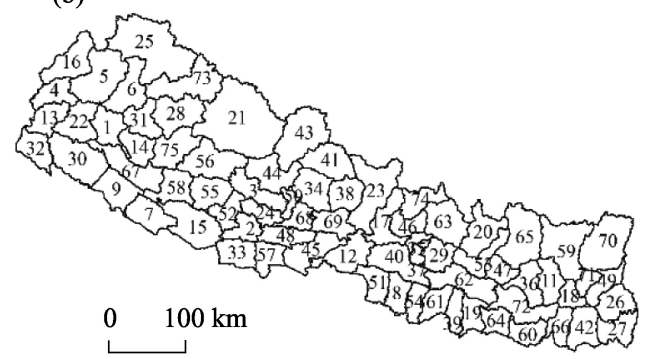

(c)

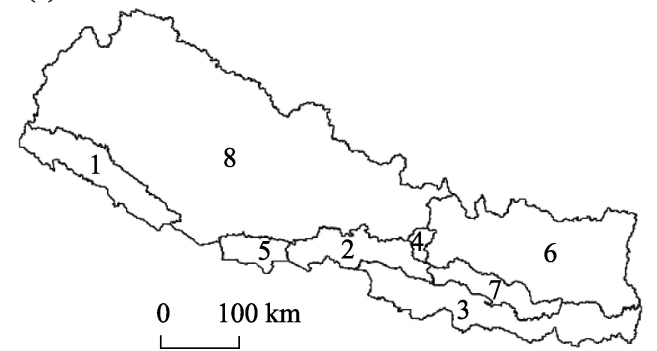

Figure 1 Map showing altitudinal (a) and administrative boundaries (this study used population data based on 75 district level for the period between 1970 and 2010) (b) as well as population data for eight regions within Nepal (c) between 1910 and 1960 (modified after Paudel et al., 2017) 
temperature of Nepal rose by $1.8^{\circ} \mathrm{C}$ between 1975 and 2006, an average rate of increase of $0.06^{\circ} \mathrm{C} /$ year (Malla, 2009). Average annual precipitation is $1,600 \mathrm{~mm}$; rainfall trends shows that $80 \%$ of precipitation occurs in the monsoonal seasons between June and September (Gautam, 2008). Nepal is an agricultural country that has 16 main soil types, including humic and chromic cambisols (Dijkshoorn and Huting, 2009).

Nepal encompassed a range of internal administrative regions throughout different historical periods. Thus, using historical population data, we determined eight major administrative regions within the country which were used in this study to reconstruct agricultural land changes between 1910 and 1960: 1, Far-Western Tarai; 2, Central Inner Tarai; 3, Eastern Tarai; 4, Kathmandu Valley; 5, Mid-Western Tarai; 6, Eastern Hills; 7, East Inner Tarai; and 8, Western Hills (Figure 1c). We also utilized five development regions, 14 zones, and 75 administrative-level districts for our reconstructions between 1970 and 2010 (Figure 1b) (Paudel et al., 2017).

Among the majority of the people in Nepal involved in agricultural activities, most use traditional cultivation methods. Thus, over the last century, changes in agricultural land use have tracked population expansion across the country. At the same time, both cropping systems and other trends within Nepal have varied based on geographical location and climatic conditions. In the Tarai regions of the country, for example, rice is mainly cultivated along with wheat and maize, while maize and millet are the dominant crops in the Hill region as well as planted rice, wheat, and cash crops (Chapagain, 2006). Buckwheat, barley, and potato farming are popular in the Mountain region alongside animal husbandry, while of the three ecological zones within Nepal, the Tarai region has the highest crop productivity proportion because of its favorable geographical location, fertile land, and good climatic conditions.

\subsection{Reconstruction algorithm}

Building on a number of previous global, national, and regional-level historical reconstructions of agricultural and cropland cover (Ramankutty and Foley, 1999; Pongratz et al., 2008; Klein Goldewijk et al., 2011; He et al., 2012; He et al., 2013; Wei et al., 2015; Li et al., 2016; Paudel et al., 2017), we collated historical literature and existing datasets for Nepal that cover the last 100 years. In this study, all actively cultivated cropland area was regarded as agricultural land, which excluded pasture and rangeland. The detailed algorithm used in this study is described in Figure 2. First, due to the absence of national datasets, we collated historical statistical data for agricultural land that covers the period between 1910 and 1960 from the HYDE 3.1 dataset. Second, we culled agricultural land spatial datasets (30 $\mathrm{m}$ grids) from Paudel et al. (2017) for the analysis of agricultural land status between 1970 and 2010. Third, we collected national-level agricultural land spatial datasets for 1978 (LRMP, 1986), as well as data on elevation, climate, soil types, population density, and slope. These parameters were all used for the assessment of land suitability for cultivation following modification with the established approach presented by Paudel et al. (2017). We then combined all parameters to generate an agricultural land allocation model and used this to divide land area into $30 \mathrm{~m}$ grids for the period between 1910 and 1960. We then generated a series of novel datasets and analyzed them in tandem with the same standard reconstructed datasets between 1970 and 2010. This approach enabled us to complete a long-term analysis of agricultural land cover in Nepal over the last 100 years. 


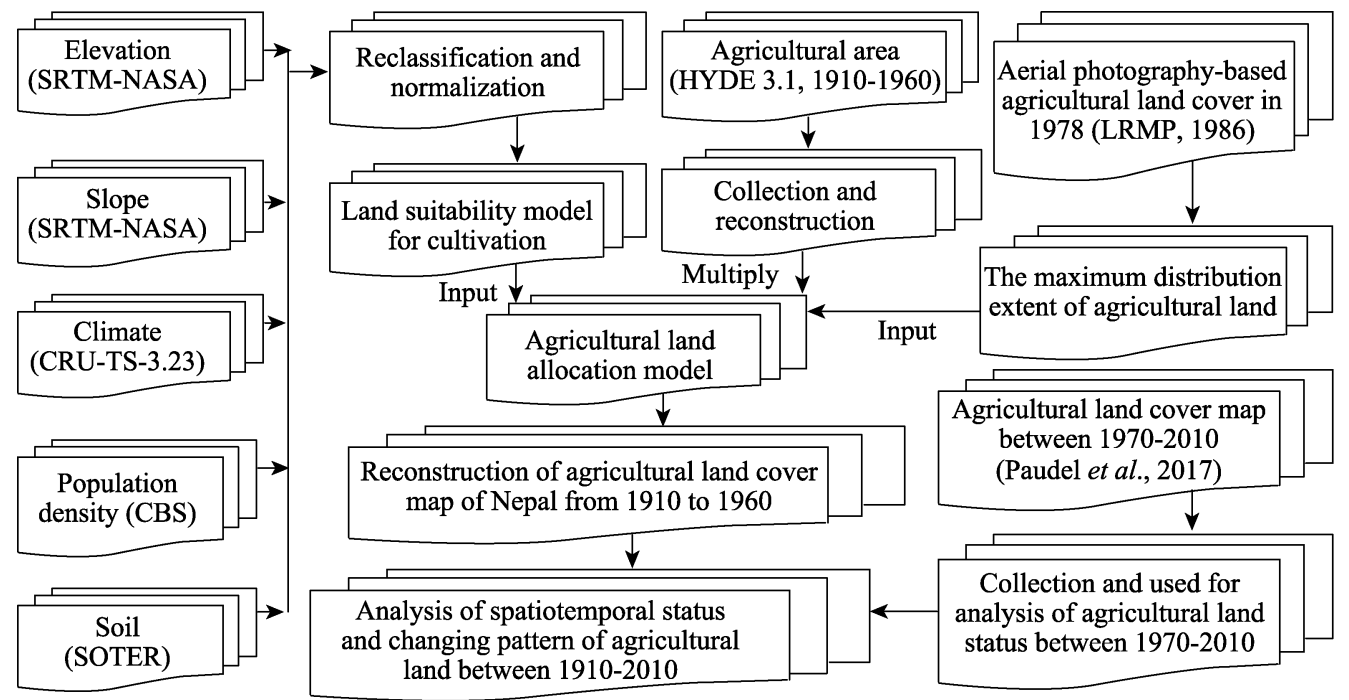

Figure 2 The algorithm used in this study for reconstructing agricultural land cover over the last 100 years (modified from Paudel et al., 2017)

\subsection{Data sources}

To enable the spatiotemporal reconstruction of historical agricultural land change in Nepal, we used a variety of datasets from different sectors and included information relating to land spatial and inventory data, as well as slope, elevation, soil types, population density, and climate records. This information was collated from a range of different sources; details of the datasets we used are summarized in Table 1. During the reconstruction of agricultural land cover, due to the lack of government records, we obtained statistical areas for the period between 1910 and 1960 from the HYDE 3.1 dataset (Klein Goldewijk et al., 2011), and adapted $30 \mathrm{~m}$ spatial resolution datasets for the period between 1970 and 2010 from Paudel et al. (2017).

Table 1 Details of the datasets used in this study

\begin{tabular}{llccccc}
\hline \multicolumn{1}{c}{ Data category } & $\begin{array}{c}\text { Spatial } \\
\text { coverage }\end{array}$ & $\begin{array}{c}\text { Temporal } \\
\text { coverage }\end{array}$ & Unit & $\begin{array}{c}\text { Original } \\
\text { resolution }\end{array}$ & $\begin{array}{c}\text { Re-gridded } \\
\text { resolution }\end{array}$ & Data sources \\
\hline LRMP-LULC & National & $1978-1979$ & $\mathrm{~m}$ & $240 \mathrm{~m}$ & $30 \mathrm{~m}$ & LRMP, 1986 \\
Mean annual temperature & Global & $1901-2010$ & ${ }^{\circ} \mathrm{C}$ & $0.5^{\circ}$ & $30 \mathrm{~m}$ & CRU-TS-3.23 \\
Mean annual precipitation & Global & $1901-2010$ & $\mathrm{~mm}$ & $0.5^{\circ}$ & $30 \mathrm{~m}$ & CRU-TS-3.23 \\
Population density & District & $1911-2011$ & $\mathrm{~km}^{2}$ & - & $30 \mathrm{~m}$ & CBS, Nepal \\
Elevation & Global & 2015 & $\mathrm{~m}$ & $30 \mathrm{~m}$ & $30 \mathrm{~m}$ & SRTM-NASA \\
Slope & Global & 2015 & $\circ$ & $30 \mathrm{~m}$ & $30 \mathrm{~m}$ & SRTM-NASA \\
Soil & National & 2009 & $\mathrm{~km}$ & $1 \mathrm{~km}$ & $30 \mathrm{~m}$ & $\begin{array}{c}\text { SOTER } \\
\text { Agricultural land (HYDE 3.1) }\end{array}$ \\
National & $1910-1960$ & $\mathrm{~km}^{2}$ & - & - & Klein Goldewijk \\
et al. (2011)
\end{tabular}

Spatial data for agricultural land cover in 1978 were obtained from the LRMP, and were used to determine the maximum extent of agricultural land area. Specifically, HYDE 3.1 agricultural land datasets were obtained from Klein Goldewijk et al. (2011) and used as the basis for our reconstructions. Climate datasets from the Climatic Research Unit (CRU-TS-3.23) 
were used to obtain estimates for mean annual temperature and precipitation (Harris et al., 2014); we used average mean temperature and precipitation for each stage of this study. The US National Aeronautics and Space Administration (NASA) has released open-access shuttle radar topography mission (SRTM) digital elevation model data at $30 \mathrm{~m}$ resolution, which we used for elevations and converted to slope data. We obtained soil data from the soil and terrain (SOTER) database for Nepal (Dijkshoorn and Huting, 2009), while historical population data for this period were obtained from the Central Bureau of Statistics, Kathmandu, Nepal (CBS, 1958, 1961, 1971, 1981, 1991, 2001, 2012).

\subsection{Spatially explicit allocation methods}

The area of agricultural land in Nepal has expanded over the period of this investigation, leading to its present-day status. Thus, to analyze the long-term status of agricultural land over time, we used data for the period between 1970 and 2010 extracted from Paudel et al. (2017) and applied the same mature, spatially-explicit allocation method used previously by these workers to reconstruct agricultural land cover between 1910 and 1960. LRMP agricultural land cover datasets were used to determine the maximum extent of agricultural land cover between 1910 and 1960, because this is the most extensive record for Nepal prior to 1978. A Boolean agricultural extent cover map, $W_{\text {agri }}(i)$, was then obtained to illustrate agricultural land area; a value of 1 was used to indicate the presence of agricultural land and a value of 0 was used to denote absence. Because the spatial extent of agricultural land in each grid is dependent on natural phenomena ( $\mathrm{Li}$ et al., 2016), we followed the approach advocated by Paudel et al. (2017) and incorporated geographical conditions, including elevation, slope, soil type, population density, and climatic factors, to assess spatial weighting and to determine areas of land suitable for agriculture (Paudel et al., 2017).

We defined the upper limit of the extent of potential agricultural land area in each $30 \mathrm{~m}$ grid cell at an elevation of $4,500 \mathrm{~m}$ and a slope of $30^{\circ}$ based on a previous study that evaluated Nepal and the Central Himalayas (Paudel et al., 2017; Wu et al., 2017). We then calculated the relationship between agricultural land, elevation, slope, and climate for the eight regional-levels between 1910 and $1960, k_{n}(n=1 ; 2 ; 3 ; \ldots ; 8)$, based on Eqs. 1, 2, and 3, respectively, all adapted from Paudel et al. (2017). We used monthly mean climate record values (i.e., precipitation and temperature) for each stage, including mean values for 1910 for the period between 1901 and 1910, mean values for 1920 for the period between 1911 and 1920, and so on, up until 1960. Finally, we performed a population density calculation using Eq. 4 adapted from Paudel et al. (2017) to determine the suitability of land for agriculture in grid cell $i$ across the eight regions, $k_{n}(n=1 ; 2 ; 3 ; \ldots 8)$, between 1910 and 1960 .

$$
E^{\prime}(i)=\frac{E-E_{\min }}{E_{\max }-E_{\min }}
$$

In this expression, $E^{\prime}(i)$ is the normalized value of the elevation for land suitable for cultivation in grid $i$, while $E$ denotes the original value of grid $i, E_{\max }$ is the maximum elevation value of grid $i$, and $E_{\min }$ denotes the minimum elevation value of grid $i$.

$$
S^{\prime}(i)=\frac{S-S_{\min }}{S_{\max }-S_{\min }}
$$

In this expression, $S^{\prime}(i)$ refers to the normalized value of the slope of land suitable for cultivation in grid $i$, while $S$ is the original slope value of grid $i, S_{\max }$ is the maximum slope value 
of grid $i$, and $S_{\min }$ is the minimum slope value of grid $i$.

$$
C^{\prime}(i)=\frac{C-C_{\min }}{C_{\max }-C_{\min }}
$$

In this expression, $C^{\prime}(i)$ refers to the normalized climate value (i.e., temperature and precipitation) for the suitability of land for agriculture in grid $i$, while $C$ is the original climate value of grid $i, C_{\max }$ is the maximum climate value of grid $i$, and $C_{\min }$ is the minimum climate value of grid $i$.

$$
P^{\prime}(i, t)=\frac{P-P_{\min }}{P_{\max }-P_{\min }}
$$

In this expression, $P^{\prime}(i, t)$ is the normalized value of population density determining the suitability of land for agriculture in grid $i$ in year $t$, while $P$ is the original value for grid $i, P_{\max }$ is the maximum population density value of grid $i$, and $P_{\min }$ is the minimum population density value of grid $i$.

The dominant soil type in a region is another key factor that determines the suitability of land for cultivation. On this basis, we classified soil types into one of two groups, either having potential as agricultural land or unsuitable. We then assigned a binary value of 1 to denote potential agricultural land $\left(S o i l_{\text {suit }}\right)$, or 0 if unsuitable; we applied this approach across the 16 major soil categories in the SOTER database (Dijkshoorn and Huting 2009).

Thus, using the five factors described above, and the Boolean extent of agricultural land cover map $W_{\text {agri }}(i)$ was determined to illustrate the area of land suitable for agriculture. The spatial weighting of agricultural land in each grid was then calculated using Eq. 5, adapted from Paudel et al. (2017), as follows:

$$
W(i, t)=W_{\text {agri }}(i) \cdot \operatorname{Soil}_{\text {suit }}(i) \cdot\left(1-E^{\prime}(i)\right) \cdot\left(1-S^{\prime}(i)\right) \cdot C^{\prime}(i) \cdot P^{\prime}(i, t)
$$

In this expression, $W(i, t)$ refers to the weighted area of a region allocated to agricultural land in grid $i$. We normalized $W(i, t)$ for region $k_{n}$ to ensure that the total weighting for a particular region was equal to one; this was done using Eq. 6 adapted from Paudel et al. (2017) as follows:

$$
R(i, t)=W(i, t) / \sum_{i} W(i, t)
$$

We then used Eq. 7 to estimate the agricultural land area within each $30 \mathrm{~m} \times 30 \mathrm{~m}$ grid cell. This expression was adapted from Paudel et al. (2017), as follows:

$$
\operatorname{Agri}(i, t)=R(i, t) \cdot \operatorname{area}\left(k_{n}, t\right)
$$

In this expression, Agri $(i, t)$ refers to the agricultural land area of grid $i$ in year $t$, while area $\left(k_{n}, t\right)$ is the agricultural land area of region $k_{n}$ in year $t$.

Once we had determined total agricultural land area, excess area was removed and a loop was implemented to allocate the total until all grids met the prescribed limit of $0.0009 \mathrm{~km}^{2}$. We looped this allocation process for agricultural land area for the years 1910, 1920, 1930, 1940, 1950, and 1960, while data meeting the same methodological standards were extracted from Paudel et al. (2017) to cover the years 1970, 1980, 1990, 2000, and 2010. This complete dataset enabled analysis of agricultural land change over the last 100 years in Nepal.

\section{Results}

\subsection{Changes in agricultural land area at the national level}

Reconstructions show that agricultural land area across Nepal increased from $15.12 \times 10^{3}$ 
$\mathrm{km}^{2}$ in 1910 to $43.88 \times 10^{3} \mathrm{~km}^{2}$ in 2010. However, while there has been an overall national trend towards increasing agricultural land area (Figure 3), this expansion has varied at different times and can be divided into three stages. There was a period of slow growth between 1910 and 1950 , followed by a period of rapid growth between 1950 and 1980, and

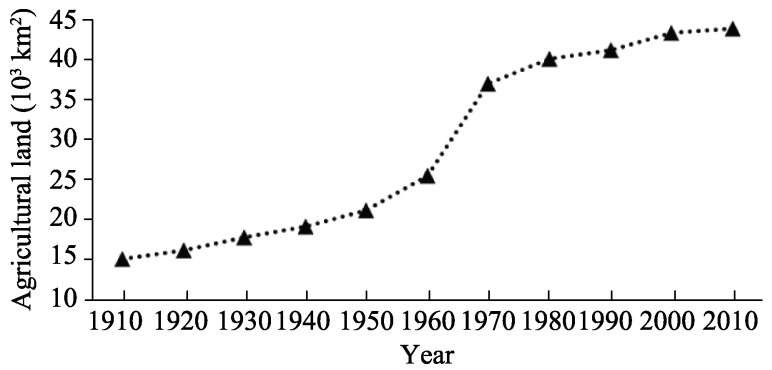

Figure 3 Reconstructions of agricultural land area in Nepal between 1910 and 2010

a final period of steady growth between 1980 and 2010 .

\subsubsection{Slow growth: between 1910 and 1950}

The total area of agricultural land increased slightly over the first stage of this period, by $1.04 \times 10^{3} \mathrm{~km}^{2}$, from $15.12 \times 10^{3} \mathrm{~km}^{2}$ in 1910 to $16.16 \times 10^{3} \mathrm{~km}^{2}$ in 1920 . During the second stage of this period, between 1920 and 1930, agricultural land area increased slightly more than during the first stage, changing from $16.16 \times 10^{3} \mathrm{~km}^{2}$ in 1920 to $17.74 \times 10^{3} \mathrm{~km}^{2}$ in 1930. Agricultural land area increased between 1930 and 1940 by $1.43 \times 10^{3} \mathrm{~km}^{2}$, rising from $17.74 \times 10^{3} \mathrm{~km}^{2}$ to $19.17 \times 10^{3} \mathrm{~km}^{2}$, while there was also an increase from $19.17 \times 10^{3}$ $\mathrm{km}^{2}$ to $21.13 \times 10^{3} \mathrm{~km}^{2}$ during the fourth stage of the study, between 1940 and 1950 . Overall, agricultural land expansion during this period took place at a low rate; there are several reasons for this, discussed below in more detail.

\subsubsection{Rapid growth: between 1950 and 1980}

Data show that over this period the agricultural land area in Nepal increased at a higher rate than earlier (Figure 3). Indeed, between 1950 and 1960, the rate of change was higher than during the previous four study stages; over this period the area of agricultural land increased from $21.13 \times 10^{3} \mathrm{~km}^{2}$ to $25.44 \times 10^{3} \mathrm{~km}^{2}$, the second highest expansion seen in Nepal in the last 100 years and an increase of $4.31 \times 10^{3} \mathrm{~km}^{2}$ compared to the previous stage. Similarly, during the sixth stage of this study, between 1960 and 1970, agricultural land area also increased rapidly from $25.44 \times 10^{3} \mathrm{~km}^{2}$ in 1960 to $37.03 \times 10^{3} \mathrm{~km}^{2}$ in 1970 . Over this period, agricultural land area increased by $11.59 \times 10^{3} \mathrm{~km}^{2}$, the highest recorded increase in Nepal over the last 100 years. There are several reasons for this change, discussed in more detail below. Finally, during the seventh study stage, between 1970 and 1980 , agricultural land area increased by $3.12 \times 10^{3} \mathrm{~km}^{2}$, from $37.03 \times 10^{3} \mathrm{~km}^{2}$ in 1970 to $40.15 \times 10^{3} \mathrm{~km}^{2}$ in 1980 .

\subsubsection{Steady growth: between 1980 and 2010}

Data show that between 1980 and 2010 there was a steady increase in the agricultural land area of Nepal (Figure 3). During the eighth stage of this study, between 1980 and 1990, this increase was less than in the seventh stage, from $40.15 \times 10^{3} \mathrm{~km}^{2}$ in 1980 to $41.16 \times 10^{3} \mathrm{~km}^{2}$ in 1990. The area covered by agricultural land during the ninth stage, between 1990 and 2000 , increased by $2.15 \times 10^{3} \mathrm{~km}^{2}$, from $41.16 \times 10^{3} \mathrm{~km}^{2}$ to $43.31 \times 10^{3} \mathrm{~km}^{2}$, while there was also an increase from $43.31 \times 10^{3} \mathrm{~km}^{2}$ to $43.88 \times 10^{3} \mathrm{~km}^{2}$ during the tenth stage of this study, between 2000 and 2010. Our reconstructions resulted in a final agricultural land area of $43.88 \times 10^{3} \mathrm{~km}^{2}$ in 2010 , the maximum recorded for the entire study. 


\subsection{Changes in agricultural land area at the eco-regional level}

The three major eco-regions (Mountain, Hill, and Tarai) of Nepal were utilized in this study as part of our analysis of agricultural land area distribution. Data show that of the 75 government declared districts in Nepal, 16 are in the Mountain region (mostly located in the northern part of the country), 39 are in the Hill region (located across the middle part of the country), and the remaining 20 are in the Tarai region (on plains in the southern part of the country).

On the basis of these divisions, results show that the distribution of agricultural land varied in a very similar way in the Tarai and Hill regions in the period between 1910 and 1960 , while there was a higher rate of expansion in the Tarai region between 1970 and 1990. In later stages, however, between 1990 and 2010, the Hill region tended to contain more agricultural land as a proportion of the total in Nepal, while in terms of the overall distribution of agricultural land, the Mountain region contained far less than the others throughout all the stages we investigated. Data also reveal a temporal trend towards increasing agricultural land area in all three eco-regions between 1910 and 2010 (Figure 4).

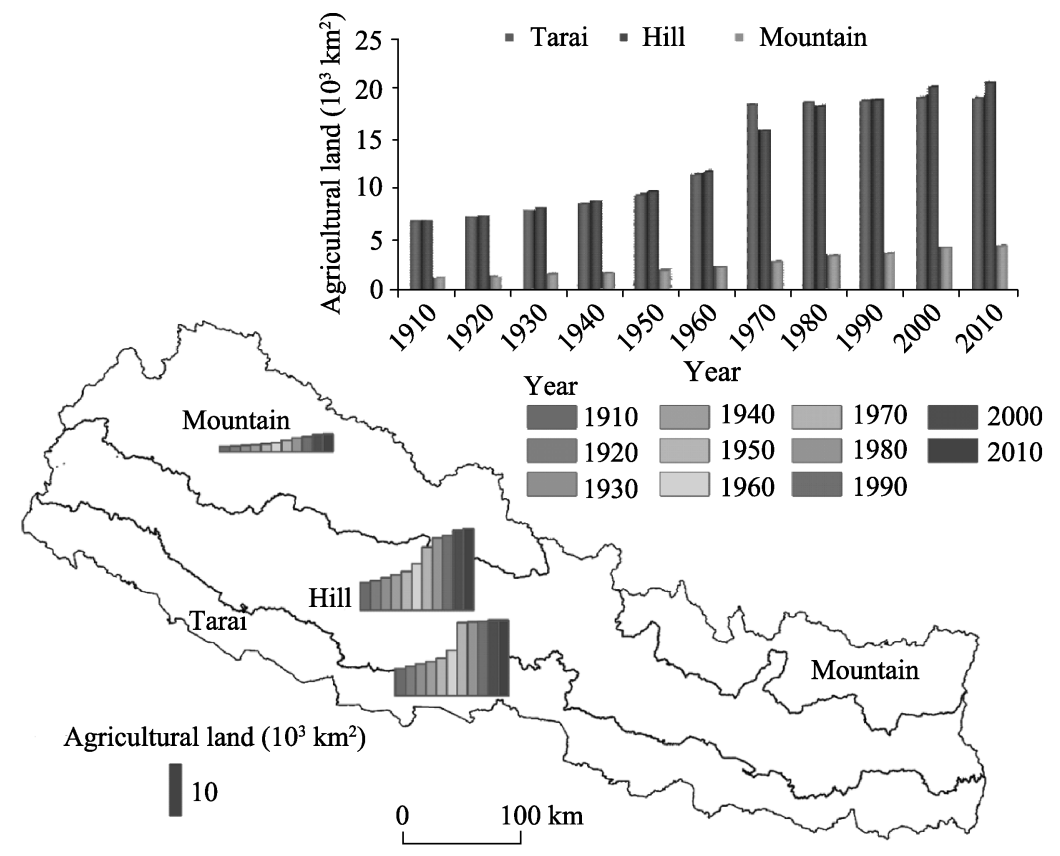

Figure 4 Trends in agricultural land area expansion between 1910 and 2010 across the three eco-regions of Nepal

Agricultural land area has tended to increase across the country as a whole, while in individual regions, more of this LULC was present in the Hill region in very early stages, up until 1960. At the same time, however, the area of agricultural land was higher in the Tarai region compared to the Hill region between 1970 and 1990. Trends in later stages show a slight decline in agricultural land area in the Tarai region as well as an increasing trend in the Mountain and Hill regions.

\subsection{Changes in agricultural land area in development regions}

There are five development regions in Nepal, classified as first level administrative units. We therefore assessed changes in the status of agricultural land within the five administra- 
tive regions that comprise this country, the Eastern Development Region (EDR), the Central Development Region (CDR), the Western Development Region (WDR), the Mid-Western Development Region (MWDR), and the Far-Western Development Region (FWDR) (Paudel et al., 2017). The results of this study show a smoothly increasing trend in agricultural land area in each of these regions (Figure 5).

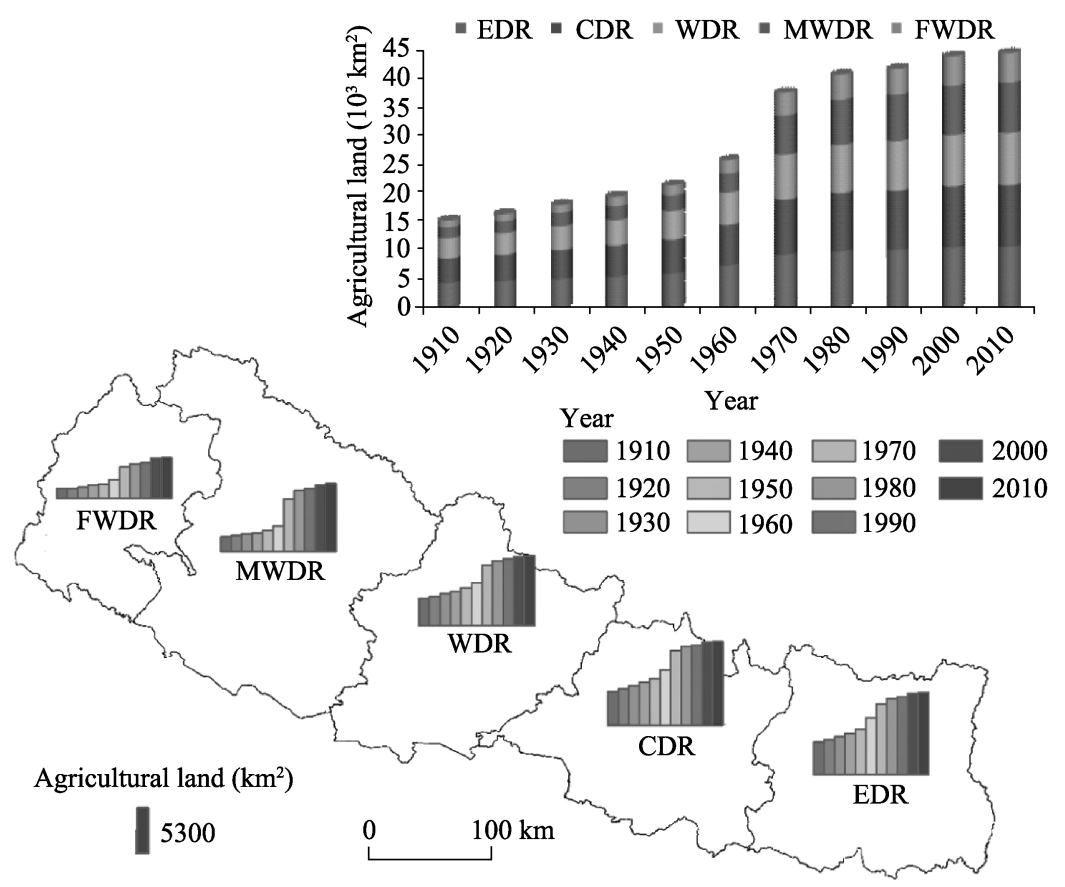

Figure 5 Trends in the expansion of agricultural land area between 1910 and 2010 in the five development regions of Nepal. Note: EDR refers Eastern Development Region, CDR for Central Development Region, WDR for Western Development Region, MWDR for Mid-Western Development Region, and FWDR for Far-Western Development Region in Nepal.

Reconstructions of agricultural land area for the five development regions revealed changes between 1910 and 2010. The agricultural land area of the EDR changed from $4.20 \times$ $10^{3} \mathrm{~km}^{2}$ to $10.46 \times 10^{3} \mathrm{~km}^{2}$ between 1910 and 2010 , while that of the CDR changed in the same way, increasing from $4.30 \times 10^{3} \mathrm{~km}^{2}$ to $10.68 \times 10^{3} \mathrm{~km}^{2}$ over the study period. Similarly, the agricultural area of the WDR increased by $3.51 \times 10^{3} \mathrm{~km}^{2}$ to $8.95 \times 10^{3} \mathrm{~km}^{2}$ between 1910 and 2010; a similar trend was seen in the MWDR, an increase from $1.90 \times 10^{3}$ $\mathrm{km}^{2}$ to $8.66 \times 10^{3} \mathrm{~km}^{2}$ between 1910 and 2010 . The situation was slightly different in the FWDR where there was an increase from $1.21 \times 10^{3} \mathrm{~km}^{2}$ to $5.14 \times 10^{3} \mathrm{~km}^{2}$ between 1910 and 2010. The largest rate of increase was seen in the CDR across every stage because this region contains more plains and areas favorable for crop cultivation than the other four.

\subsection{Changes in spatial patterns at the national level}

This study has presented a series of historical reconstructions of agricultural land change in Nepal over the last 100 years divided into 11 time slices (i.e., at ten-year intervals) at high resolution $(30 \mathrm{~m})$. Our spatial agricultural land reconstructions reveal that during the first study stage that commenced in 1910, this land use type was mainly concentrated in the Hill and Tarai regions of Nepal (Figure 6a), in particular in the central and eastern areas. The 
overall area of agricultural land increased slightly during the second (1920) (Figure 6b), third (1930) (Figure 6c), and fourth (1940) (Figure 6d) study stages, in a similar fashion to the first stage. However, in the fifth (1950) (Figure 6e) and sixth (1960) stages (Figure 6f) there was a more rapid increase in agricultural land area than previously, with significantly higher spatial expansion in both Hill and Tarai regions. During the sixth stage in particular, results show a noticeable expansion in agricultural land within the Tarai region. One reason for this expansion has to do with the fact that before 1950 this region experienced major problems with malaria, prior to a major government eradication initiative (Dhimal et al., 2014). The same period (1950 to 1951) witnessed the overthrow of the Rana family autocracy in Nepal (Whelpton, 2005), unification, the advent of modern democracy in 1951, and the initiation of government land settlement programs in the Tarai region (Ojha, 1983). It is clear that between 1950 and 1960, agricultural land in Nepal was reclaimed at a high rate, particularly intensively in the Tarai and Hill regions.
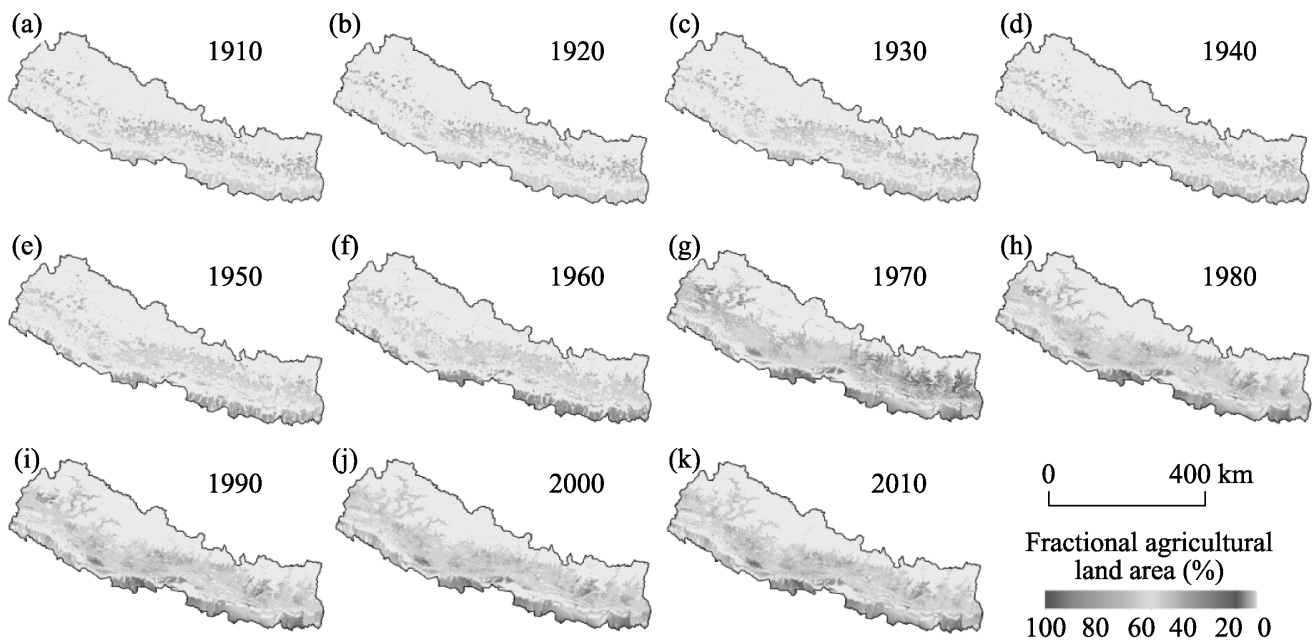

Figure 6 The spatial status of agricultural land cover in Nepal at $30 \mathrm{~m}$ resolution between 1910 and 2010 (a-k, with g-k taken from Paudel et al., 2017)

During the seventh stage (1970), spatial distribution data show that agricultural land was still being reclaimed at an unprecedented rate, especially in the Tarai region of Nepal (Figure $6 \mathrm{~g}$ ) and in central and western areas. By this time, a large area of agricultural land was concentrated in the eastern Tarai, while comparatively less was present in the mid- and far-western areas (Paudel et al., 2017). Data show that within the time period of this study, over the last 100 years, the rate of agricultural land expansion was the highest between 1960 and 1970. Indeed, agricultural land area also increased significantly during the eighth stage (1980), especially in the Hill region, in mid- and far-western areas of the Tarai region, and in the eastern and far-western Hill region (Figure 6h) (Paudel et al., 2017). During the ninth stage (1990) (Figure 6i), agricultural land use had become more intensified in the Tarai region, but had not expanded much in mid- and far-western areas of the Hill and Mountain regions due to their climatic conditions and harsh topography. During the tenth stage (Figure 6j) of this study (2000), a fractionally higher rate of expansion was seen in the Hill and Mountain regions compared to the Tarai, while in the last stage (2010) (Figure 6k), agricultural land continued to expand at a steady rate, especially in the Hill and Mountain 
regions. At the same time, agricultural land cover adjacent to, and within, big cities continued to decrease due to high levels of urbanization (Thapa and Murayama, 2009, 2010).

\subsection{Spatial variation at the physiographic region level}

Due to vast topographic variations, Nepal comprises five physiographic regions: Tarai, Siwalik, and Hill, as well as Middle and High Mountain (LRMP, 1986) (Figure 7c). Based on these five physiographic regions, we describe and analyze spatial variations in agricultural land change. The spatial trend in reconstructed agricultural land cover over the last 100 years clearly shows that agricultural activities in all regions of the country have rapidly intensified (Supplementary Information Table A1).

(a)

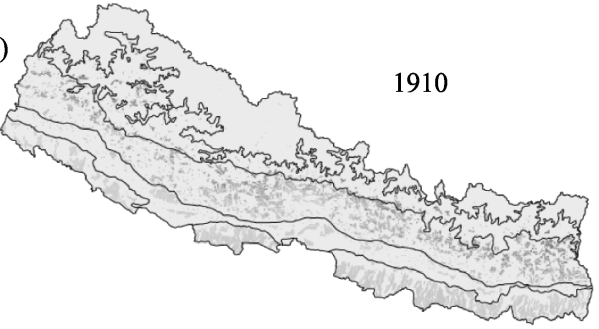

(c)

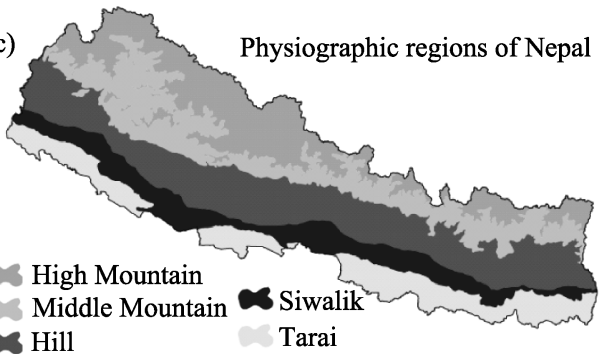

(b)
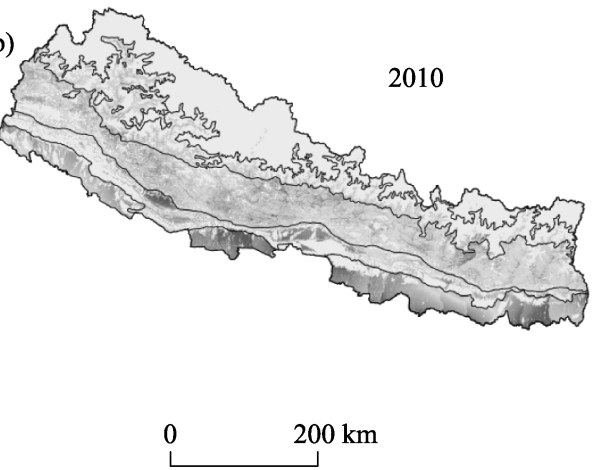

Fractional agricultural land area $(\%)$

1009080706050403020100

Figure 7 The spatial status of agricultural land cover in Nepal at the level of physiographic regions in 1910 (a) and 2010 (b)

Intensification of the agricultural land use in the High Mountain region led to five times more reclamation that previously between 1910 and 2010 , from $17.11 \mathrm{~km}^{2}$ to $95.54 \mathrm{~km}^{2}$, respectively. Similarly, spatial trends in the Middle Mountain region show variation from $946.54 \mathrm{~km}^{2}$ to $4879.59 \mathrm{~km}^{2}$ over the last 100 years, while agricultural land cover in the Hill region was $6680.71 \mathrm{~km}^{2}$ in 1910 . This area rapidly increased until 2010 when it was $17,749.91 \mathrm{~km}^{2}$. Although the pattern in the Siwalik region also shows an intensification of about 3.6 times agricultural land cover between 1910 and 2010, the most dynamic trend is seen in the Tarai region where land area increased from $6274.12 \mathrm{~km}^{2}$ to $16,771.36 \mathrm{~km}^{2}$ over the course of this study.

The spatial pattern that characterizes the first stage shows that the majority of agricultural land was previously located in the Hill region, even though the intensity of this LULC is higher in the Tarai region. Status and agricultural land patterns show that the High Mountain, Middle Mountain, and Siwalik regions experienced less agricultural activity at the start of the study period; spatial results shown that agricultural land cover in the Hill region between 1910 and 1960 was larger than in the Tarai region, while this dramatically intensified between 1970 and 1990 to a higher level than in the Hill region. This trend continued 
between 2000 and 2010 to reach a higher level of agricultural land cover than other regions of the country.

In general, agricultural land cover in the Tarai region includes more fertile soil than other physiographic regions, as well as more suitable topography for agriculture. This means that the intensification and expansion of agricultural land in southern Nepal has rapidly increased over the last 100 years, clearly reflected in spatial patterns of agricultural land between 1910 and 2010 (Figures $7 \mathrm{a}$ and $7 \mathrm{~b}$ ).

\subsection{Spatial variation within altitudinal zones}

Nepal is located in the Himalayan region. Thus, because of vast topographic and altitudinal variations, the spatial status of agricultural land cover over the last 100 years has also been directly affected by altitudinal variation and there is a close relationship between the two variables. We therefore evaluated trends and changes in the spatial intensification of agricultural land cover between 1910 and 2010 by dividing national contour lines into seven categories, below $500 \mathrm{~m}$, between $500 \mathrm{~m}$ and $1000 \mathrm{~m}$, between $1000 \mathrm{~m}$ and $1500 \mathrm{~m}$, between $1500 \mathrm{~m}$ and $2500 \mathrm{~m}$, between $2500 \mathrm{~m}$ and $3500 \mathrm{~m}$, between $3500 \mathrm{~m}$ and $4500 \mathrm{~m}$, and above $4500 \mathrm{~m}$. This enabled us to determine spatial changes in agricultural land cover based on elevation range over the last 100 years.

The southern region of Nepal is situated in the low altitudinal zone, and is called the Tarai. Contour lines show that the majority of land in this region is at elevations below $500 \mathrm{~m}$, although some areas at this height are also seen in the Siwalik, Hill, and Middle Mountain regions of the country. In terms of agricultural activities, this low altitude area is most suitable for crops, not just because of the presence of plains at low altitude but also because of fertile soil for agriculture. Thus, this zone, below $500 \mathrm{~m}$, encompasses the highest proportion of agricultural land cover nationally across all study stages (Supplementary Information Table B1).

The spatial distribution of agricultural land cover between $500 \mathrm{~m}$ and $1,000 \mathrm{~m}$ has also intensified, but to a much lesser extent than in the lower altitudinal zone. This result is obvious because this altitudinal range encompasses most of the area of the Siwalik region of Nepal which is not as suitable for agriculture as the first zone. In addition, the total area of this zone is also much lower than the first altitudinal zone. The rate of change in agricultural land over the last 100 years by altitude is presented in Figure 8 .

Spatial trends in the intensification of agricultural land cover in the belt between $1000 \mathrm{~m}$ and $1500 \mathrm{~m}$ are much higher than those between $500 \mathrm{~m}$ and $1000 \mathrm{~m}$. This zone is mostly located in the Hill region; the agricultural area of this belt has also greatly intensified in recent decades, especially after 1990. The results of this study show that agricultural area in this altitudinal zone was $3501.67 \mathrm{~km}^{2}$ in 1910 , increasing up to $8769.16 \mathrm{~km}^{2}$ by 2010 . Trends in agricultural land within the altitudinal belt between $1500 \mathrm{~m}$ and 2,500 $\mathrm{m}$ are almost the same as those between $500 \mathrm{~m}$ and $1000 \mathrm{~m}$, albeit slightly less than the in the $500 \mathrm{~m}$ and $1000 \mathrm{~m}$ belt. This zone is also characterized by a smoothly increasing rate of land reclamation, as in other altitudinal zones; the distribution of agricultural land in this altitudinal zone was $2184.11 \mathrm{~km}^{2}$ in 1910 and had increased to $7567.78 \mathrm{~km}^{2}$ by 2010 .

Although the elevation zone between $2500 \mathrm{~m}$ and $3500 \mathrm{~m}$ is characterized by less agricultural land cover overall, this has expanded and intensified over the last 100 years. Some areas within this zone lie within the Middle Mountain region, while some are within the High Mountain region where agricultural activities are difficult and the soil quality is not 
favorable for crops. As a result, the distribution of agricultural land within this altitudinal belt is less than that of its counterparts.

The spatial distribution of agricultural land in the elevation zone between $3500 \mathrm{~m}$ and $4500 \mathrm{~m}$ is low; this area was $8.31 \mathrm{~km}^{2}$ in 1910 but increased over the 100 year period of this study to $83.47 \mathrm{~km}^{2}$ by 2010 . The majority of the area encapsulated by this altitudinal belt is located in the Middle and High Mountain regions,

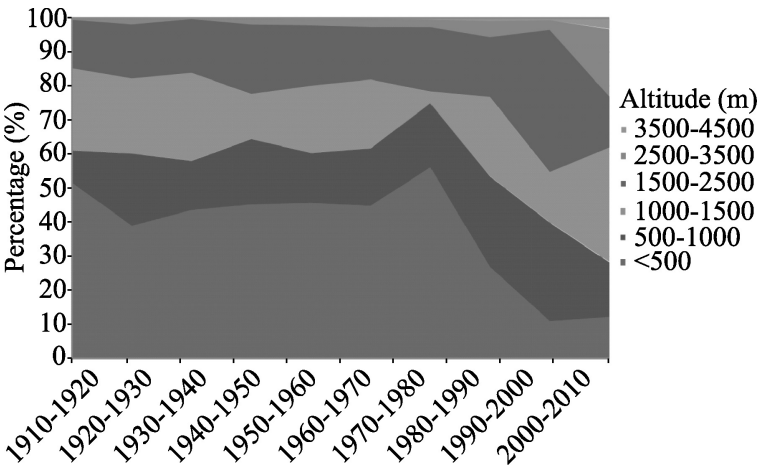

Figure 8 The altitudinal rate of change (\%) of agricultural land area in Nepal between 1910 and 2010 so this result is also obvious because of high altitude, extreme climate, and topography. Under these conditions it is very difficult for both crops and humans to survive. The cut-off point for this study was set at $4500 \mathrm{~m}$; we therefore assume that there is no agricultural land area above this altitude and so no spatial distribution map at this height was reconstructed. It is noteworthy that this may have created some uncertainties in estimates for the distribution of total agricultural land area; the additional uncertainties in this study are briefly discussed in Supplementary Information C.

\section{Discussion}

\subsection{Management, potential drivers, policy implications, and future directions}

Throughout the historical period, the government of Nepal has managed the transition from highly fertile zones to agricultural land, starting in the 1950s after the launch of a malaria eradication program and supported by a favorable political system following democratic reforms in 1950 and 1951. In this generally favorable political climate, the government of Nepal started to settle landless people in the Tarai region in the so-called 'Rapti Project'. As part of this resettlement program, people were moved from the Hill to the Tarai region (Ojha, 1983). Indeed, as evidenced by the historical literature, a tropical climate and malaria eradication programs in the Tarai region are usually thought to be the main causative factors of agricultural land expansion (Ojha, 1983). However, other factors were likely also to have been just as important, including the government policy to resettle people in the Tarai region, the attractiveness of the highly fertile soils in this area, the low cost and high profitability of agricultural activities in lowland areas compared to hilly slopes, and a high rate of population growth. Throughout previous stages, these types of programs and factors led to remarkably high rates of land reclamation for agriculture in Nepal. However, poor management in recent decades has led to the conversion of highly built-up areas as well as the abandonment of some regions. For these reasons, it is necessary to develop, effectively implement, and manage coherent land use policies.

The regional-level study presented here for Nepal shows that, socioeconomic, neighborhood, climatic, and topography-related factors have mainly driven agricultural land area changes (Paudel et al., 2016a). In addition, population density, the migration of foreign labor, distance from roads, settlements, and rivers, as well as precipitation, temperature, elevation, 
soil, and land slope must also be taken into account. It is clear that the relative influence of these factors were different in historical times; different drivers have come to the forefront at different times, reflecting the changing status of agricultural land at the regional and national scale. High population growth over the last 100 years (Figure 9a), for example, has played a key role in agricultural land expansion, while climatic conditions also relate, directly and indirectly, to changes in this LULC (Figure 9b). Additional important factors include the actions and policies of government, directly related to agricultural land expansion across Nepal throughout the period of this study, especially in the Tarai region. In recent decades, agricultural land areas in this region that are adjacent to the east-west highway have been extensively converted into built-up areas as a direct result of government policies and their implementation. It is very important that the government puts in place suitable land use policies and amends them based on sustainable management strategies that are linked to the economy and the lifestyles of the populations. This process can be aided by the adequate management of LUCC, especially agricultural land, both currently and into the future.

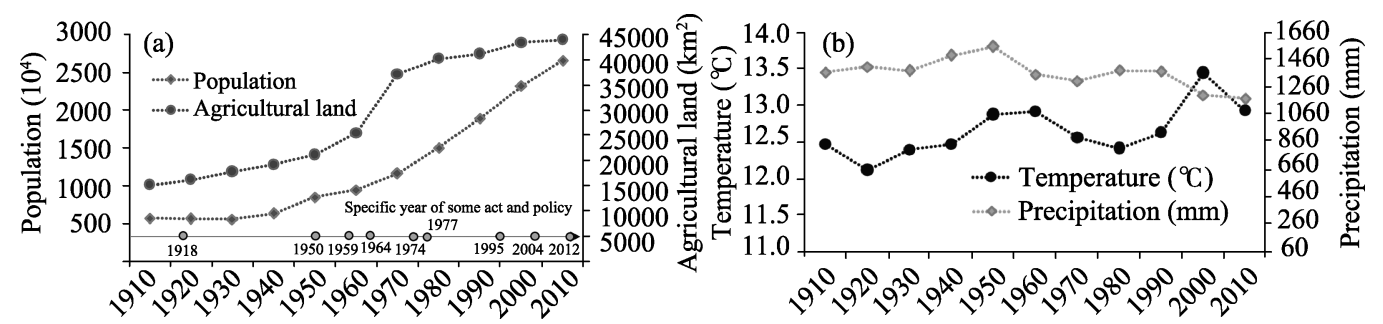

Figure 9 Variations in population, agricultural land area (a), temperature and precipitation (b) over the last 100 years in Nepal. A number of acts and government policies have been superimposed onto this figure.

Throughout the historical period in Nepal, a number of settlement policies for land management were applied at different stages. For example, between 1769 and 1815, the government attempted to reclaim waste land through forced labor (Regmi, 1972). The most important of these government policies was initiated towards the end of the 18th century (Ojha, 1983); however, between 1814 and 1816, land settlement policies came almost to a standstill due to the Anglo-Nepalese war and the process was not re-started until after 1920 when people were again encouraged to settle in the Tarai region (Ojha, 1983). After 1950, the rate of agricultural land reclamation rose rapidly and the government developed a series of land use laws and policies in an attempt to effectively manage LUCC (Sharma and Khanal, 2010). Examples include the 'Birta Abolition Act 1959', the 'Land Survey and Measurement Act 1963', the 'Land Act 1964', the 'Range Land Nationalization Act 1974', the 'Trust Corporation (Guthi) Act 1976', the 'Land Revenue Act 1977', and the 'Land Acquisition Act 1977' (FAO, 2010) (Figure 9). Building on these historical developments, a new set of land use policies was developed in 2012 (NLUP, 2012) that emphasize the appropriate use of land (Paudel et al., 2016a). In addition, the government of Nepal developed a National Agricultural Policy 2004, an Irrigation Policy 2004, and an Agricultural Perspective Plan (1995-2015) aimed at enabling the effective management of agricultural land across the country. However, many problems have not been solved appropriately because of the inadequate implementation of laws and policies (Paudel et al., 2016a).

The reconstructions presented here show that significant areas of agricultural land surrounding big cities have been converted to built-up areas over recent decades, especially in the Tarai region. However, the rate of agricultural land abandonment has also increased in 
the Hill and Mountain regions of the country, due to the lack of appropriate government policies, implementation, and management. We argue that if the government does not take appropriate action with regard to the management of agricultural land. It is likely that the current high rate of conversion to built-up areas will continue in the future, alongside the abandonment of land based on its geographical location. The new national land use project (NLUP, 2012) aims to solve some of agricultural land management issues (Paudel et al., 2016a) by developing integrated land use planning and zoning across major land categories (i.e., agricultural, residential, forest, commercial, industrial, public, and other areas). This land use project will also aid the effective management of agricultural land. We argue that it will be necessary to focus in the future on the implementation of policies aimed at increasing agricultural productivity, as well as enhancing commercially competitive agriculture (Paudel et al., 2016a) in tandem with the combined management of agricultural land, biodiversity conservation, and natural resources. It is also necessary to take the rapidly growing national population into account as part of the effective management of agricultural land in Nepal.

\subsection{Marked changes and regional variation over the last 100 years}

The results of this study reveal a series of remarkable changes in agricultural land cover across Nepal over the last 100 years. In particular, data show that agricultural land area in 1910 was around three times less than in 2010. Based on our historical reconstructions of agricultural land cover across Nepal, three stages characterized by marked changes can be highlighted. Between 1950 and 1960, agricultural land cover in the country rose by $4.31 \times$ $10^{3} \mathrm{~km}^{2}$. This equates to an increase of $11.59 \times 10^{3} \mathrm{~km}^{2}$ between 1960 and 1970 compared to the period between 1950 and 1960, and was followed by a peak of $3.12 \times 10^{3} \mathrm{~km}^{2}$ between 1970 and 1980. Several possible factors could explain these changes.

In the first place, as discussed above, there were major problems with malaria in Nepal prior to 1950, especially in the Tarai region. However, from 1950 onwards, the government initiated an intensive program to eradicate this disease (Dhimal et al., 2014). Other political changes also took place at the same time, including the 1950-1951 overthrow of the Rana family autocracy (Whelpton, 2005), unification and the advent of modern democracy in 1951, and the initiation of government-sponsored land settlement programs in the Tarai region (Ojha, 1983). All of these changes would have been highly conducive to agricultural land expansion in Nepal. Indeed, the period between 1951 and 1960 is often referred to as 'the Transitional Period' in terms of national agricultural land expansion (Ojha, 1983). Following the initiation of Malaria eradication and the land settlement program between 1950 and 1960, the government then strongly supported the expansion of agricultural land between 1960 and 1970, especially in the Tarai, and Hill and regions of the country. This government support led to the highest level of land use expansion seen in the 100 year duration of this study. Between 1950 and 1970, the government of Nepal freely allocated waste lands in the Tarai region to anyone who undertook to reclaim them for settlement, allowing the payment of less tax over a four- to ten-year period (Regmi, 1972).

Turning to regional variations, results show that the over the last 100 years, the southern part of Nepal has experienced the highest rate of increase in agricultural land area. At the same time, however, the fractional spatial distribution of this change reveals that the rate of increase had declined by 2010. There are a number of human-induced reasons for this, including a high rate of urbanization in the plains area, the establishment of industrial areas in 
the southern part of the country, and an increasing trend towards population growth in the regions (Paudel et al., 2017). Thus, status and trends in agricultural land reconstruction changes varied between different administrative areas (i.e., regions, zones, and districts) between 1910 and 2010. Reconstructions show that far-western areas, including the Tarai regional districts Kailali and Kanchanpur, had less agricultural land before 1950; this was also the case in the Hill district of Baitadi and the Mountain district of Darchula, both of which were rapidly reclaimed between 1950 and 2010. In more western areas of the country, in regions such as Kaski, Syanja, Tanahu, and Lamjung, the reuse of land and the intensification of agricultural areas took place at a steadier rate than in other parts of the country. In contrast, central and eastern districts of the Tarai region, including Morang, Sunsari, and Jhapa, now have more agricultural land than they did earlier, much of which has been heavily reclaimed since the 1950s. These regions are amongst the most suitable in Nepal for cultivating crops as they are characterized by flat slopes and fertile land. Agricultural land cover in these regions intensified during the later time periods of this study, while the situation in Hill and Mountain districts such as Khotang, Solukhumbu, and Sankhuwasabha meant that intensification of this LULC type did not occur until after 2000. Agricultural land in some of these regions has even been recently abandoned because of the absence of irrigation, labor shortages, and reductions in income from traditional agriculture (Paudel et al., 2016a). The area of agricultural land in the Kathmandu Valley, for example, increased until the 1960 s but declined in recent decades due to high levels of urbanization.

Reconstructions show that, until 2010, the lowest area of agricultural land was in the Karnali zone, while the largest area of agricultural land was in the Lumbini zone. These results were both expected because the latter zone encompasses a favorable area for crop cultivation, while the former is characterized by harsh topographic and climatic conditions (Paudel et al., 2017). Finally, reconstructions over the last 100 years for different districts and regions of the country are significantly different from one another because of topographic, rapid population growth, and climatic factors.

\section{Conclusions}

The historical reconstruction study presented in this paper considered changes in spatial patterns of agricultural land in Nepal over the last 100 years (i.e., encompassing the period between 1910 and 2010). This was achieved via land suitability assessment and a land allocation model and generated a series of historical datasets. Agricultural land reconstruction between 1910 and 1960 was based on national-level statistical data and encompassed eight regional-levels of population figures analyzed at both national and regional levels. In contrast, we used district-level statistical data for the period between 1970 and 2010, analyzing this at both national and different regional levels. Thus, on the basis of these models, we reconstructed and developed high resolution $(30 \mathrm{~m})$ agricultural land cover maps for Nepal, covering ten-year intervals between 1910 and 2010.

The results of our reconstructions strongly suggest that agricultural land in Nepal expanded significantly between 1910 and 2010. This expansion varied at different times; between 1910 and 1950, for example, less growth in agricultural land area was seen, from $15.12 \times 10^{3} \mathrm{~km}^{2}$ to $21.13 \times 10^{3} \mathrm{~km}^{2}$, while a rapid increase was seen between 1950 and 1980 , from $21.13 \times 10^{3} \mathrm{~km}^{2}$ to $40.15 \times 10^{3} \mathrm{~km}^{2}$, respectively. Steady growth was seen between 1980 and 2010 , from $40.15 \times 10^{3} \mathrm{~km}^{2}$ in 1980 to $43.88 \times 10^{3} \mathrm{~km}^{2}$ in 2010 . The spatial dis- 
tribution of agricultural land during the initial 1910 stage showed that less area was present proportionally in the Tarai and Hill regions; the Jhapa, Rupandehi, and Banke districts in the Tarai region as well as the Ilam, Kaski, and Surkhet districts in the Hill region had less agricultural land area. However, increasing land area intensified and this trend became most marked in the Tarai region after the 1950s, as well as in the central Hill and Mountain regions of the country. Data show that, over recent decades, especially after the 1990s, there has been a slight decrease in the rate of land area conversion to agricultural land, especially around the capital city (Kathmandu) and in other areas surrounding big cities (Biratnagar, Pokhara, Butwal, Kohalpur, Nepaljung). The high rate of population growth, government policies, and climate have all played key roles in influencing agricultural land cover over this period. The historical spatial dataset for the last 100 years presented in this paper will prove very useful for the future analysis of agricultural land impacts at local, regional, and national scales, as well as for analyses of carbon emissions and climatic modeling.

\section{Acknowledgments}

The authors are thankful to Ms. Wu Xue, Dr. Wang Zhaofeng, Prof. He Fanneng of IGSNRR, Prof. Ai Likun of Institute of Tibetan Plateau Research, Prof. Narendra R. Khanal, Prof. Padma C. Poudel, Associate Prof. Prem S. Chapagain and Assistant Prof. Sher B. Gurung of Central Department of Geography, Tribhuvan University of Nepal and Mr. Basanta R. Shrestha, Dr. Arun B. Shrestha, Mr. Kabir Uddin and Mr. Liu Rongkun of ICIMOD, Nepal for their guidance, help, sharing their valuable datasets, suggestions and comments.

\section{References}

CBS, 1958. National Population Census, 1911, 1920, 1930, 1941, and 1952/54. Government of Nepal. Kathmandu, Nepal: Central Bureau of Statistics.

CBS, 1961. National Population Census, 1961. Government of Nepal. Kathmandu, Nepal: Central Bureau of Statistics.

CBS, 1971. National Population Census, 1971. Government of Nepal. Kathmandu, Nepal: Central Bureau of Statistics.

CBS, 1981. National Population Census, 1981. Government of Nepal. Kathmandu, Nepal: Central Bureau of Statistics.

CBS, 1991. National Population Census 1991. Government of Nepal, National Planning Commission Secretariat. Kathmandu, Nepal: Central Bureau of Statistics.

CBS, 2001. National Population Census 2001. Government of Nepal, National Planning Commission Secretariat. Kathmandu, Nepal: Central Bureau of Statistics.

CBS, 2012. National Population and Housing Census 2011 (National Report). Government of Nepal, National Planning Commission Secretariat. Kathmandu, Nepal: Central Bureau of Statistics.

Chapagain P S, 2006. Involution or evolution? Conceptualizing the changes in farming system of Eastern Nepal. Himalayan Review, 37: 1-17.

Chen J, Chen J, Liao A P et al., 2015. Global land cover mapping at 30m resolution: A POK-based operational approach. ISPRS Journal of Photogrammetry and Remote Sensing, 103(1): 7-27.

Dhimal M, Ahrens B, Kuch U 2014. Malaria control in Nepal 1963-2012: Challenges on the path towards elimination. Malaria Journal, 13: 1-14.

Dijkshoorn K, Huting J, 2009. Soil and terrain database for Nepal (Report). ISRIC - World Soil Information, Wageningen, $21 \mathrm{p}$. with data set.

FAO, 2010. Land Use Policy and Planning. Food and Agriculture Organization of the United Nations UN Complex, Pulchowk, Nepal, p.40.

Foley J A, DeFries R, Asner G P et al., 2005. Global consequences of land use. Science, 309(5734): 570-574.

Fuchs R, Herold M, Verburg P H et al., 2013. A high-resolution and harmonized model approach for reconstructing and analysing historic land changes in Europe. Biogeosciences, 10(3): 1543-1559.

Fuchs R, Verburg P H, Clevers J G P W et al., 2015. The potential of old maps and encyclopaedias for reconstructing historic European land cover/use change. Applied Geography, 59: 43-55.

Gautam J, 2008. Country Report on the State of the Nepal's Plant Genetic Resources for Food and Agriculture. 
Commission of Genetic Resources for Food and Agriculture. Food and Agriculture Organization of the United Nations. p.91.

Harris I, Jones P D, Osborn T J et al., 2014. Updated high-resolution grids of monthly climatic observations: The CRU TS3.10 Dataset. International Journal of Climatology, 34(3): 623-642.

He F N, Li S C, Zhang X Z, 2012. Reconstruction of cropland area and spatial distribution in the mid-Northern Song Dynasty (AD1004-1085). Journal of Geographical Sciences, 22(2): 359-370.

He F N, Li S C, Zhang X Z, 2015. A spatially explicit reconstruction of forest cover in China over 1700-2000. Global and Planetary Change, 131: 73-81.

He F N, Li S C, Zhang X Z et al., 2013 Comparisons of cropland area from multiple datasets over the past 300 years in the traditional cultivated region of China. Journal of Geographical Sciences, 23(6): 978-990.

Klein Goldewijk K, Beusen A, Doelman J et al., 2017. Anthropogenic land use estimates for the Holocene: HYDE 3.2. Earth System Science Data, 9(2): 927-953.

Klein Goldewijk K, Beusen A, Van Drecht G et al., 2011. The HYDE 3.1 spatially explicit database of human induced global land use change over the past 12,000 years. Global Ecology and Biogeography, 20(1): 73-86.

Klein Goldewijk K, Ramankutty N, 2004. Land cover change over the last three centuries due to human activities: The availability of new global data sets. GeoJournal, 61(4): 335-344.

Lambin E F, Turner B L, Geist H J et al., 2001. The causes of land-use and land-cover change: Moving beyond the myths. Global Environmental Change, 11(4): 261-269.

Li S C, He F N, Zhang X Z, 2016. A spatially explicit reconstruction of cropland cover in China from 1661 to 1996. Regional Environmental Change, 16(2): 417-428.

Li S C, Wang Z F, Zhang Y L, 2017. Crop cover reconstruction and its effects on sediment retention in the Tibetan Plateau for 1900-2000. Journal of Geographical Sciences, 27(7): 786-800.

LRMP, 1986. Land Utilization Report. Land Resource Mapping Project, Kenting Earth Science Canada and Department of Topography, Government of Nepal, Kathmandu, Nepal, p.112.

Malla G, 2009. Climate change and its impact on Nepalese agriculture. The Journal of Agriculture and Environment, 9: 62-71.

NLUP, 2012. National Land Use Policy. Ministry of Land Reform and Management, Government of Nepal, Kathmandu, Nepal. p.17.

Ojha D P, 1983. History of land settlement in Nepal Tarai. Contribution to Nepalese Studies, 11(1): 21-44.

Paudel B, Gao J G, Zhang Y L et al., 2016a. Changes in cropland status and their driving factors in the Koshi River Basin of the Central Himalayas, Nepal. Sustainability, 8(9): 933.

Paudel B, Zhang Y L, Li S C et al., 2016b. Review of studies on land use and land cover change in Nepal. Journal of Mountain Science, 13(4): 643-660.

Paudel B, Zhang Y L, Li S C et al., 2017. Spatiotemporal reconstruction of agricultural land cover in Nepal from 1970 to 2010. Regional Environmental Change, 17(8): 2349-2357.

Pitman A J, Avila F B, Abramowitz G et al., 2011. Importance of background climate in determining impact of land-cover change on regional climate. Nature Climate Change, 1(9): 472-475.

Pongratz J, Reick C, Raddatz T et al., 2008. A reconstruction of global agricultural areas and land cover for the last millennium. Global Biogeochemical Cycles, 22(3): 1-16.

Ramankutty N, Foley J A, 1999. Estimating historical changes in global land cover: Croplands from 1700 to 1992. Global Biogeochemical Cycles, 13(4): 997-1027.

Regmi M C, 1972. A Study in Nepali Economic History 1768-1846. Delhi, India: Adroit Publishers.

Sharma K, Khanal S, 2010. A review and analysis of existing legal and policy issues related to land tenure and agriculture in Nepal. Kathmandu University Journal of Science, Engineering and Technology, 6(2): 133-141.

Thapa R B, Murayama Y, 2009. Examining spatiotemporal urbanization patterns in Kathmandu Valley, Nepal: Remote sensing and spatial metrics approaches. Remote Sensing, 1(3): 534-556.

Thapa R B, Murayama Y, 2010. Drivers of urban growth in the Kathmandu valley, Nepal: Examining the efficacy of the analytic hierarchy process. Applied Geography, 30(1): 70-83.

Wei X Q, Ye Y, Zhang Q et al., 2015. Methods for cropland reconstruction based on gazetteers in the Qing Dynasty (1644-1911): A case study in Zhili province, China. Applied Geography, 65: 82-92.

Whelpton J, 2005. A History of Nepal. Cambridge University Press.

World Bank, 2015. Nepal total population and GDP per capita (current US\$), 2015. World Bank, http://data.worldbank.org/country/nepal.

Wu X, Gao J G, Zhang Y L et al., 2017. Land cover status in the Koshi River Basin, Central Himalayas. Journal of Resources and Ecology, 8(1): 10-19.

Yang X H, Jin X B, Guo B B et al., 2015. Research on reconstructing spatial distribution of historical cropland over 300 years in traditional cultivated regions of China. Global and Planetary Change, 128: 90-102.

Zhang X Z, He F N, Li S C, 2013. Reconstructed cropland in the mid-eleventh century in the traditional agricultural area of China: Implications of comparisons among datasets. Regional Environmental Change, 13(5): 969-977. 


\section{Supplementary Information}

\section{Spatiotemporal changes in agricultural land cover in Nepal over the last 100 years}

\section{Basanta PAUDEL ${ }^{1,2}{ }^{*}$ ZHANG Yili ${ }^{1,2,3}$, LI Shicheng ${ }^{1,2,4}$, LIU Linshan ${ }^{1}$}

1. Key Laboratory of Land Surface Pattern and Simulation, Institute of Geographic Sciences and Natural Resources Research, CAS, Beijing 100101, China;

2. University of Chinese Academy of Sciences (UCAS), Beijing 100049, China;

3. CAS Center for Excellence in Tibetan Plateau Earth Sciences, Beijing 100101, China;

4. School of Public Administration, China University of Geosciences, Wuhan 430074, China

Supplementary Information A Variations at the level of physiographic regions

Table A1 Reconstructed agricultural land cover $\left(\mathrm{km}^{2}\right)$ for the physiographic regions of Nepal between 1910 and 2010

\begin{tabular}{ccccccc}
\hline & \multicolumn{7}{c}{ Physiographic regions and agricultural land cover $\left(\mathrm{km}^{2}\right)$} \\
\cline { 2 - 7 } Year & High Mountain & Middle Mountain & Hill & Siwalik & Tarai & Total \\
\hline 1910 & 17.11 & 946.54 & 6680.71 & 1200.31 & 6274.12 & $15,118.79$ \\
1920 & 18.27 & 1044.81 & 6984.13 & 1276.61 & 6833.21 & $16,157.03$ \\
1930 & 22.31 & 1188.61 & 7749.57 & 1399.53 & 7377.23 & $17,737.25$ \\
1940 & 25.34 & 1325.21 & 8431.66 & 1493.42 & 7891.51 & $19,167.14$ \\
1950 & 31.82 & 1586.79 & 9368.73 & 1638.42 & 8498.93 & $21,124.69$ \\
1960 & 49.76 & 1976.74 & $11,268.45$ & 1855.75 & $10,286.67$ & $25,437.37$ \\
1970 & 58.03 & 3975.14 & $14,092.21$ & 3248.12 & $15,657.23$ & $37,030.73$ \\
1980 & 69.26 & 4338.67 & $15,855.25$ & 3943.14 & $15,941.03$ & $40,147.35$ \\
1990 & 74.15 & 4538.63 & $16,164.86$ & 4079.14 & $16,298.13$ & $41,154.91$ \\
2000 & 80.51 & 4746.73 & $17,594.27$ & 4251.62 & $16,640.13$ & $43,313.26$ \\
2010 & 95.54 & 4879.59 & $17,749.91$ & 4382.08 & $16,771.36$ & $43,878.48$ \\
\hline
\end{tabular}

Supplementary Information B Variation across altitudinal zones

Table B1 Altitudinal variations in reconstructed agricultural land cover $\left(\mathrm{km}^{2}\right)$ in Nepal between 1910 and 2010

\begin{tabular}{cccccccc}
\hline \multirow{7}{*}{ Year } & $<500 \mathrm{~m}$ & $50-1000 \mathrm{~m}$ & $1000-1500 \mathrm{~m}$ & $1500-2500 \mathrm{~m}$ & $2500-3500 \mathrm{~m}$ & $3500-4500 \mathrm{~m}$ & Total \\
\cline { 2 - 8 } 1910 & 6821.42 & 2465.32 & 3501.67 & 2184.11 & 137.96 & 8.31 & $15,118.79$ \\
1920 & 7355.21 & 2564.81 & 3751.83 & 2334.27 & 141.94 & 8.97 & $16,157.03$ \\
1930 & 7969.04 & 2901.16 & 4099.29 & 2588.33 & 169.24 & 10.19 & $17,737.25$ \\
1940 & 8590.48 & 3108.13 & 4468.75 & 2817.21 & 171.42 & 11.15 & $19,167.14$ \\
1950 & 9473.89 & 3483.75 & 4727.68 & 3221.03 & 206.15 & 12.19 & $21,124.69$ \\
1960 & $11,437.63$ & 4119.19 & 5579.45 & 3992.95 & 286.59 & 21.56 & $25,437.37$ \\
1970 & $16,623.65$ & 6077.13 & 7917.42 & 5803.41 & 575.41 & 33.71 & $37,030.73$ \\
1980 & $18,367.34$ & 6664.57 & 8026.27 & 6398.74 & 645.02 & 45.41 & $40,147.35$ \\
1990 & $18,637.33$ & 6932.51 & 8261.12 & 6576.86 & 693.57 & 53.52 & $41,154.91$ \\
2000 & $18,873.26$ & 7556.34 & 8578.28 & 7482.47 & 755.73 & 65.18 & $43,313.26$ \\
2010 & $18,942.35$ & 7647.16 & 8769.36 & 7567.78 & 868.36 & 83.47 & $43,878.48$ \\
\hline
\end{tabular}




\section{Supplementary Information C Uncertainty analysis}

In the absence of small and regional-scale historical statistical datasets of agricultural land for Nepal, we used the HYDE 3.1 (Klein Goldewijk et al., 2011) statistical datasets of agricultural land national level for our reconstructions. Although this usage may have led to a number of problems with the results of this study, we reconstructed agricultural land cover with a resolution of $30 \mathrm{~m}$ following an established approach between 1910 and 1960 and derived a number of standard datasets between 1970 and 2010 (Paudel et al., 2017). In addition, to the further absence of national and small scale spatiotemporal datasets over longer timescales, we were not able to validate and assess the accuracy of our datasets between 1910 and 1960 because we used HYDE historical datasets for this period. Further appropriate high-resolution datasets for agricultural land cover are not available for comparison and validation. Thus, the datasets we reconstructed for between 1910 and 1960 may also contain uncertainties, which may create further issues with evaluating the actual status of agricultural land cover between 1910 and 1960. These differences and uncertainties were less in the datasets we derived for between 1970 and 2010 (Paudel et al., 2017), as these were already validated and tested for accuracy. Finally, in the absence of station-based historical climate data for Nepal between 1910 and 1960, we adapted a dataset from the CRU (CRU-TS-3.23) (Harris et al., 2014) and used it to calculate the suitability of land for agriculture. It is noteworthy that CRU datasets were mainly developed at the global scale; however, due to a lack of historical datasets, these were applied at the regional level, which may also have led to some uncertainties in evaluating the actual status of agricultural land cover between 1910 and 1960 in Nepal.

\section{References}

Harris I, Jones P D, Osborn T J et al., 2014. Updated high-resolution grids of monthly climatic observations - the CRU TS3.10 Dataset. International Journal of Climatology, 34(3): 623-642.

Klein Goldewijk K, Beusen A, Van Drecht G et al., 2011. The HYDE 3.1 spatially explicit database of human induced global land use change over the past 12,000 years. Global Ecology and Biogeography, 20(1): 73-86.

Paudel B, Zhang Y L, Li S C et al., 2017. Spatiotemporal reconstruction of agricultural land cover in Nepal from 1970 to 2010. Regional Environmental Change, 17(8): 2349-2357. 